\title{
Increasing cloud cover in the 20th century: review and new findings in Spain
}

\author{
A. Sanchez-Lorenzo ${ }^{1}$, J. Calbó ${ }^{2}$, and M. Wild ${ }^{1}$ \\ ${ }^{1}$ Institute for Atmospheric and Climate Science, ETH Zurich, Zurich, Switzerland \\ ${ }^{2}$ Group of Environmental Physics, University of Girona, Girona, Spain
}

Correspondence to: A. Sanchez-Lorenzo (arturo.sanchez@env.ethz.ch)

Received: 15 March 2012 - Published in Clim. Past Discuss.: 5 April 2012

Revised: 26 June 2012 - Accepted: 28 June 2012 - Published: 20 July 2012

\begin{abstract}
Visual observations of clouds have been performed since the establishment of meteorological observatories during the early instrumental period, and have become more systematic and reliable after the mid-19th century due to the establishment of the first national weather services. During the last decades a large number of studies have documented the trends of the total cloud cover (TCC) and cloudy types; most of these studies focus on the trends since the second half of the 20th century. Due to the lower reliability of former observations, and the fact that most of this data is not accessible in digital format, there is a lack of studies focusing on the trends of cloudiness since the mid-19th century. In the first part, this work attempts to review previous studies analyzing TCC changes with information covering at least the first half of the 20th century. Then, the study analyses a database of cloudiness observations in Southern Europe (Spain) since the second half of the 19th century. Specifically, monthly TCC series were reconstructed since 1866 by means of a so-called parameter of cloudiness, calculated from the number of cloudless and overcast days. These estimated TCC series show a high interannual and decadal correlation with the observed TCC series originally measured in oktas. After assessing the temporal homogeneity of the estimated TCC series, the mean annual and seasonal series for the whole of Spain and several subregions were calculated. The mean annual TCC shows a general tendency to increase from the beginning of the series until the 1960s; at this point, the trend becomes negative. The linear trend for the annual mean series, estimated over the $1866-2010$ period, is a highly remarkable (and statistically significant) increase of $+0.44 \%$ per decade, which implies an overall increase of more than $+6 \%$ during the analyzed period. These results are in line
\end{abstract}

with the majority of the trends observed in many areas of the world in previous studies, especially for the records before the 1950s when a widespread increase of TCC can been considered as a common feature.

\section{Introduction}

Clouds are the main cause of variability of shortwave and longwave radiation at the Earth's surface and the top of the atmosphere, and consequently play a major role in the global energy balance. It is well known that clouds can contribute both to cooling and warming the Earth's surface, e.g. due to their high albedo and capacity to absorb infrared radiation, respectively (e.g. Mace et al., 2006; Zelinka and Hartmann, 2010). Despite their importance, there are still large uncertainties in the trends of clouds since pre-industrial times and their response to anthropogenic and natural forcings. In fact, the response of cloudiness caused by the increase in the greenhouse gases and the cloud feedbacks are currently the primary source of inter-model differences in equilibrium climate sensitivity (Randall et al., 2007). Therefore, knowledge of variations of clouds may contribute to improving our comprehension of the role of clouds in contemporary climate change, as for example in the context of the causes of the dimming/brightening phenomenon (Wild, 2009, 2012).

Part of the limitations regarding the analysis of decadal trends of clouds comes from the well-known difficulties to record objective observations of clouds and quantify cloudiness variations. Satellite data provide an excellent spatial and temporal coverage on global or regional scales, but the assessment of trends is limited to the last decades as systematic 
observations from satellites started only in the 1980s. Moreover, the temporal homogeneity of the measurements has been questioned due to calibration problems (Norris, 2005; Evan et al., 2007), as well as large inconsistencies with respect to their trends (Cermak et al., 2010). On the other hand, traditional ground level visual observations of cloudiness provide an excellent source to study trends of cloudiness on decadal and multi-decadal time scales. Observations of cloudiness at weather stations have been worldwide performed systematically by observers since the mid-19th century, when the national meteorological offices started to be established. In addition, sky state conditions had already been recorded during the early instrumental period, i.e. the observations made prior to the mid-19th century, which have also been proven to be a useful source of data in climate studies (Moberg et al., 2003; Auchmann et al., 2012). However, traditional observations lack objectivity, e.g. regarding the estimation of total cloud cover (TCC) and the determination of cloud types. Equally, changes of observing practices, times of observations, and observers, can introduce biases that affect the homogeneity of the series. The subjective nature of these observations and their uncertainties has jeopardized the reliability of trends derived from these series (e.g. Karl and Steurer, 1990). Therefore, these difficulties result in a limited number of climatic studies focusing on the trends of cloudiness, especially if compared with studies of other climatological variables such as temperature or precipitation.

However, still some studies have analyzed traditional cloud observations, especially TCC, in search of long-term trends since the mid-20th century up to the present. Results of these studies show different temporal patterns, although a distinction must be made between studies based on ground observations over land and oceans. Over land, there are a variety of observed trends, which sometimes vary according to the cloud types analyzed. Overall, for studies reporting an increase in TCC we can mention, among others, the works for Russia during the 1951-2000 period (Khlebnikova and Sall, 2009), US in the second half of the 20th century (Angell, 1990; Sun, 2003; Dai et al., 2006), and Ireland during the period 1950s-1998 (Pallé and Butler, 2001, 2002b). But the works reporting a decrease in TCC are more frequent: e.g. for China during the 1954-2005 period (Kaiser, 2000; Xia, 2010), Tibetan Plateau during the 1961-2005 period (You et al., 2010), Italy during the 1951-1996 period (Maugeri et al., 2001), southern India during the 1952-1997 period (Biggs et al., 2007), South Africa during the 19602005 period (Kruger, 2007) and Poland during the 19502000 period (Wibig, 2008). Equally, other studies report nonsignificant trends in the TCC series, as for example for Australia during the 1957-2007 period (Jovanovic et al., 2011). Finally, a worldwide analysis from about 5400 land stations for the 1971-1996 period reveals a slight decrease of TCC in the global average series, with the largest decrease found in South America, and an increase restricted to the Arctic area
(Warren et al., 2007). On the other hand, observations taken aboard ships across the oceans suggest a general increase of the TCC since the second half of the 20th century, although this upward trend is claimed to be spurious due to an unproven observational artifact (e.g. see Warren et al., 1988; Norris, 1999; Bedacht et al., 2007; Eastman et al., 2011).

For Spain, in Southwestern Europe, there are few studies focusing on the trends of clouds since the second half of the 20th century. Sanchez-Lorenzo et al. (2009, hereafter referred as SL09) analyzed a high-quality data set of TCC over the Iberian Peninsula, based on traditional visual observations of cloudiness during the 1961-2004 period, concluding that TCC has decreased during this period. These findings were confirmed by Calbó and Sanchez-Lorenzo (2009) after analyzing different products providing cloud cover data from the mid-1980s to the beginning of the 2000s.

Overall, the previously reported studies are limited to data starting in the second half of the 20th century. In fact, there is a lack of studies analyzing the TCC series before the 1950s, especially because the major part of the data still needs to be digitized, e.g. as a major part of the records for other climatic variables (Brönnimann et al., 2006). Nevertheless, during the last decades some isolated attempts have been made in order to study global and regional changes from historical records of clouds over land and oceans. Unfortunately, a compilation of all these studies is still lacking, and consequently an overall picture of the reported trends is missing.

The first objective of this study is to present a comprehensive review of existing studies reporting long-term trends of TCC series before the second half of the 20th century; this synthetic review configures Sect. 2 . The second objective is to generate a long-term dataset of homogeneous TCC series over Spain since the latter third of the 19th century, and analyze this series in search of trends. The different datasets and methods used to assess the decadal trends in TCC over Spain are described in Sect. 3, while results of the analysis are presented in Sect. 4. Finally, in Sect. 5 these results are discussed and conclusions of the study are summarized, together with some hints for further research.

\section{A review of the TCC trends before the second half of the 20th century}

In this section a summary of the trends observed in the TCC series available before the second half of the 20th century are presented. Table 1 includes some details of the reviewed publications, i.e. location, periods, signs for the reported trends, and source of the series (over land or oceans). In this table, only the studies reporting results for TCC series are included, and consequently other works using only other cloud variables such as frequencies of sky conditions or estimates of TCC inferred from other climate variables (e.g. rainy days, sunshine duration, etc.) are not considered. Some of the studies summarized here have already been partially described 
Table 1. Summary of the reviewed studies reporting trends of TCC before the second half of the 20th century, including information regarding the location/region studied, source of the observations (land or ocean), period, and sign and magnitude of the trends (\%) over the specific periods of each study.

\begin{tabular}{|c|c|c|c|c|c|c|}
\hline Location/region & Reference & Source & Sites & Period & Sign & Trend $(\%)$ \\
\hline USA & Henderson-Sellers (1986b) & Land & 77 & $1900-1954$ & + & $+7^{*}$ \\
\hline USA & Henderson-Sellers and McGuffie (1989) & Land & 77 & 1900-1984 & + & $+11^{*}$ \\
\hline USA & Karl and Steurer (1990) & Land & 127 & 1900-1986 & + & $\mathrm{n} / \mathrm{a}$ \\
\hline USA & Croke et al. (1999) & Land & 23 & 1900-1987 & + & $+10^{*}$ \\
\hline Canada & McGuffie and Henderson-Sellers (1988) & Land & 41 & 1901-1954 & + & $+6^{*}$ \\
\hline Canada & Henderson-Sellers and McGuffie (1989) & Land & 41 & 1901-1982 & + & $+8^{*}$ \\
\hline North America & Henderson-Sellers (1989) & Land & 143 & $1900-1984$ & + & $+8^{*}$ \\
\hline North America & Henderson-Sellers (1992) & Land & 143 & 1900-1984 & + & +9.6 \\
\hline Europe & Henderson-Sellers (1986a) & Land & 58 & 1900-1954 & + & $\mathrm{n} / \mathrm{a}$ \\
\hline Europe & Henderson-Sellers (1992) & Land & 58 & 1900-1987 & + & +6.3 \\
\hline Alpine Region & Brunetti et al. (2009) & Land & 66 & 1878-2005 & \pm & $+2 /-2$ \\
\hline Nordic European countries & Tuomenvirta et al. (2000) & Land & 36 & 1910-1995 & + & +1.5 \\
\hline Armagh, Ireland & Pallé and Butler (2002b) & Land & 1 & 1884-2000 & + & $+5^{*}$ \\
\hline Cracow, Poland & Matuszko (2003) & Land & 1 & 1906-2000 & + & $+7^{*}$ \\
\hline Cracow, Poland & Lewik et al. (2010) & Land & 1 & 1826-2005 & + & $+8^{*}$ \\
\hline NE Spain & Curto et al. (2009) & Land & 1 & 1910-2006 & + & +22 \\
\hline Russia & Sun and Groisman (2000) & Land & 223 & 1936-1999 & + & $\mathrm{n} / \mathrm{a}$ \\
\hline Australia & Jones and Henderson-Sellers (1992) & Land & 318 & 1910-1989 & + & +7 \\
\hline Australia & Henderson-Sellers (1992) & Land & 89 & 1900-1986 & + & +9.4 \\
\hline India & Henderson-Sellers and McGuffie (1989) & Land & 60 & 1900-1954 & + & $+6^{*}$ \\
\hline India & Henderson-Sellers (1992) & Land & 60 & 1900-1970 & + & +5.1 \\
\hline Global & Parungo et al. (1994) & Ocean & $\mathrm{n} / \mathrm{a}$ & 1930-1981 & + & +4.2 \\
\hline Global & Ishii et al. (2005) & Ocean & $\mathrm{n} / \mathrm{a}$ & $1900-2000$ & + & +5 \\
\hline Pacific Ocean & Wright (1986) & Ocean & $\mathrm{n} / \mathrm{a}$ & $1920-1969$ & + & +12 \\
\hline
\end{tabular}

* Trend estimates based on visual analysis of the figures, since no trend values are provided.

in the Intergovernmental Panel on Climate Change (IPCC) reports (Houghton et al., 1990, 230 pp., 1996, 62-163 pp., 2001, 148-149 pp.; Solomon et al., 2007, 275-276 pp.) and also in Pallé and Butler (2002a).

The first study reporting systematic changes in cloudiness, but still not using TCC series as such and consequently not listed in Table 1, might be attributed to Changnon (1981). In this paper the study of trends for different sky conditions (i.e. cloudless, partly cloudy and overcast conditions) were analyzed over the Midwestern US during the period 1901-1977, reporting a decrease (increase) of $26 \%$ (41\%) in cloudless (overcast) conditions. Similar results for cloudless conditions were obtained by Seaver and Lee (1987) for the whole US between 1900 and 1982.

A few years later, Henderson-Sellers and collaborators published a series of pioneering studies analyzing longterm TCC series in different areas across the world. For the US, a significant increase of about $10 \%$ in the TCC was found during the 1900-1984 period (Henderson-Sellers, 1986b, 1989; Henderson-Sellers and McGuffie, 1989). This increase shows a non-monotonic trend, as the major part of the increase occurred around the 1930s-1940s and 1960s1980s subperiods. Similar trends were confirmed by Croke et al. (1999) using a subset of the TCC series for three regions of the US during the 1900-1987 period. Equally, for Canada a systematic increase in TCC was reported between 1901 and 1982 (McGuffie and Henderson-Sellers, 1988; HendersonSellers and McGuffie, 1989; Henderson-Sellers, 1989). The observed trend (about $8 \%$ over the period considered) is slightly lower than for the US, but a sharp increase is also visible in the 1930s-1950s subperiod. Nevertheless, the observed increase after the 1960s is considerably lower in Canada than in the US, which explains the lower rate in Canada over the whole period. Finally, including both US and Canadian series, Henderson-Sellers (1992) established an increase of $9.6 \%$ of TCC in North America during the 1900-1984 period. It is noteworthy to mention that Karl and Steurer (1990) suggested that the strong increase detected in the TCC series over the US in the late 1930s and the 1940s could be the result of changes in the cloud observing practices, which changed from 3 observations per day to one observation per hour, together with a widespread relocation of weather stations to airport locations. Consequently, they concluded that this increasing period in the 1930s-1940s may be exaggerated and spurious due to biases in TCC observations, although the increase after the 1950 s can be considered as real. 
Over Europe, Henderson-Sellers (1986a, 1992) also started the systematic analysis of the long-term TCC series available since 1900 . These studies confirmed that the mean annual series shows a significant increase from 1900 to 1987 , with a trend of $+6.3 \%$ during the whole analyzed period. This increase is lower than the trend reported for North America, and with more spatial heterogeneity, as around $25 \%$ of the stations show a decreasing trend, i.e. some areas in central Europe, Norway, and southeastern Spain. Equally, the time evolution of the mean series is different compared with North America, as it shows a slight increase from 1900s to 1940 , followed by a sharp decrease in the 1940s, and a strong increase afterwards until the end of the 1970s. More recently, Brunetti et al. (2009) conducted a comprehensive analysis of the TCC series in the Alpine region and their surroundings (i.e. covering the $4-19^{\circ} \mathrm{E}, 43-49^{\circ} \mathrm{N}$ area) over the 1878-2005 period. The dataset used in this study is certainly the one with the highest quality amongst the reviewed studies, as an exhaustive homogenization was performed by means of the Craddock method, which has been proven as one of the most suitable methods to homogenize climate data (Venema et al., 2012). The results showed a general tendency towards an increase in the western region of the studied area (i.e. west of $12^{\circ} \mathrm{E}$ ) over the whole period, whereas a decrease was found in the eastern region (i.e. east of $12^{\circ} \mathrm{E}$ ), both with a magnitude of change of about $2 \%$. Note that these trends are expressed in terms of ratios with respect to the normal (multiplicative anomalies) instead of differences (additive anomalies) as used in the major part of the other studies. Consequently, no direct comparison can be done between these trend rates and the trends previously reported over Europe by Henderson-Sellers (1986a, 1992). Moreover, for the eastern Alpine region the time evolution of the TCC series shows an increase until the 1920s, followed by a decrease until the end of the analyzed period. On the other hand, in the western region there is a quasi-monotonic increase from the mid-19th century to the 1970s, only interrupted by a strong decrease in the 1940s, and with no significant trend since the 1980s until the present. On a seasonal basis, the decrease (increase) in the eastern (western) region is mainly dominated by the winter and autumn (summer) variations. Very recently, Sanchez-Lorenzo and Wild (2012) analyzed homogeneous TCC series from Switzerland, which were included inside the western region defined by Brunetti et al. (2009), during the 1885-2010 period. Their results agree with the previously described trends for the western Alpine region, although the overall increase found during the analyzed period is slightly lower (about 6\%) than the trends reported over Europe by Henderson-Sellers (1992), and mainly concentrated in the 1950s-1970s subperiod. Focusing on the Nordic countries of Europe, Tuomenvirta et al. (2000) reported a TCC trend of $+1.5 \%$ during the 1910-2005 period, with a time evolution that starts with an increase between 1910 and the late 1920s, followed by a decrease until the early 1940s and continuing with a new increase until 1990. Overall, the low rates of increase found in the Nordic countries by Tuomenvirta et al. (2000) are in line with previous results (see Fig. 4 in Henderson-Sellers, 1986a). Sun and Groisman (2000) reported an increase in TCC over Russia during the 19361999 period, although the observed trends are mainly due to changes after the 1950s. Finally, other studies focusing only on one station reported an increase in TCC since the late 19th or the beginning of the 20th centuries: i.e. in Cracow, Poland (Matuszko, 2003; Lewik et al., 2010); in Armagh, Ireland (Pallé and Butler, 2002b); and in Northeastern Spain (Curto et al., 2009). In this latter study, the authors reported a change of around 2 oktas (i.e. $25 \%$ ) in TCC during the 1910-2006 period, which turns out to be the strongest trend reported in the literature up to the present.

In Australia, the TCC series show a widespread increase between 1900 and 1989, with an overall trend of $+9.4 \%$ mainly concentrated in the 1930-1980 subperiod (Jones and Henderson-Sellers, 1992; Henderson-Sellers, 1992). For India, an increase of $5.1 \%$ is also observed during the period 1900-1970, but here the main difference with other studies is that the increase is mainly due to the positive trend observed between the 1900s and 1940s, with no major changes since the 1950s (Henderson-Sellers, 1992).

All the previous studies were restricted to land areas using observations from surface stations, which traditionally had provided more robust and systematic datasets in order to determine long-term changes in the climatic variables. Nevertheless, cloud observations from weather reports taken aboard ships have been collected by the International Comprehensive Ocean-Atmosphere Data Set (ICOADS). Specifically, the last version available (R2.5) of the ICOADS (Woodruff et al., 2011) provides global TCC data over oceans on area-weighted $2^{\circ}$ boxes since the mid- 19 th century. Using a previous version of the ICOADS, Ishii et al. (2005) reported a global increase of TCC over ocean, with a total rate of $+5 \%$ during the 1900-2000 period. The time evolution shows an overall increase since the early 1910 s, only briefly interrupted by a decrease in the 1930s and with an evident sharp increase in the 1940s. These results are in line with the trends previously reported by Parungo et al. (1994) covering the shorter 1930-1981 period, where a significant increase of $+4.2 \%$ during the analyzed period was highlighted, and with a trend for the Northern Hemisphere $(+5.8 \%)$ that was twice that for the Southern Hemisphere $(+2.9 \%)$. Focusing on the Pacific Ocean, Wright (1986) observed a stronger increase (about $+12 \%$ ) in TCC during the 1920-1969 period.

For both land and ocean trends, several issues have been pointed out regarding the quality and homogeneity of the observations, and consequently regarding the reliability of the reported trends. Detailed descriptions of the possible causes of these artifacts are beyond the scope of this review, especially because these causes remain unproven at the present. For more details on these issues, we refer to the individual studies that address and discuss them: for land observations (e.g. Henderson-Sellers, 1989, 1992; 
a

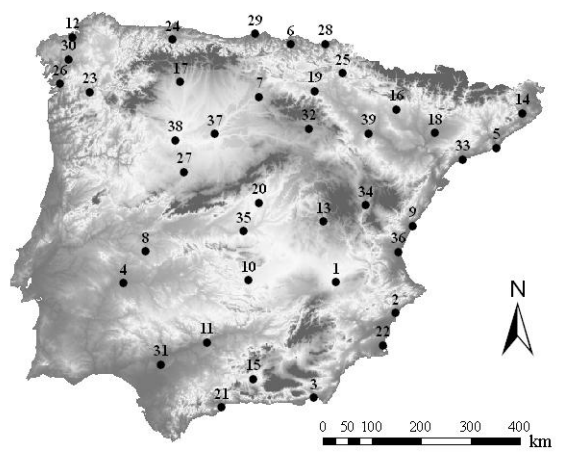

b

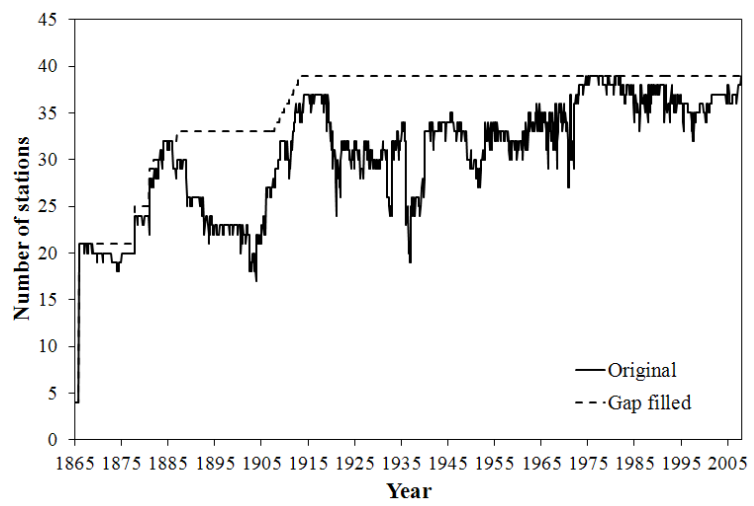

Fig. 1. (a) Location of the 39 stations with cloud observations used in this study over Spain, in southwestern Europe. The stations are numbered and their details are available in Table 2. (b) Time evolution of data availability for the TCC data set during the period 1865-2010, both for the original (solid line) and gap filled (dashed lines) series.

Henderson-Sellers and McGuffie, 1989; Karl and Steurer, 1990; Jones and Henderson-Sellers, 1992; Pallé and Butler, 2002b), and ocean observations (e.g. Elms et al., 1993; Bajuk and Leovy, 1998; Wright, 1986; Ishii et al., 2005; Eastman et al., 2011).

Overall, most of the studies reviewed suggest an increase in the TCC since the late 19th century, and in particular from the early until the mid/late-20th century, both over land and ocean. Although possible artifacts in these trends cannot be ruled out, it seems difficult to argue that these possible biases in the observations could explain the significant increases observed worldwide, as was also previously argued by Henderson-Sellers (1992).

\section{Datasets and methods to study the TCC trends in Spain}

\subsection{Cloudiness datasets}

In Spain, very few TCC series have currently records in digital format for the period before the 1960s, as pointed out by SL09, despite the abundant observations that have been taken in Spain since the 19th century. Therefore, an effort has been made to recover and digitize the TCC records in Spain following the recommendations of Brönnimann et al. (2006). Unfortunately, it was impossible to find the original observations of TCC (in oktas or tenths) made at the different meteorological stations since the 1850 s when official meteorological observations started in Spain. Instead, monthly summaries of cloudless and overcast days since 1865 were found in different volumes of the publications entitled "Resumen de las observaciones meteorológicas efectuadas en la Península" and "Boletín Mensual Climatológico", edited by the Spanish weather service (currently, AEMET) from 1865 to 1950 and after 1950, respectively. Nowadays, AEMET establishes that a day is defined as clear (overcast) if the mean TCC from the 3 daily observations is less than 1.5 (more than 6.5 oktas). The same or very similar thresholds but in tenths, i.e. less (more) than 2 (8) tenths for clear (overcast) conditions, were used since the beginning of these monthly summaries previously cited. Thus, the monthly series of cloudless and overcast days for the 39 stations with records within the period 1865-1960 were digitized. It is worth noting that cloudless and overcast conditions are more easily detectable by the observer than partially cloudy conditions, and consequently less sensitive to inhomogeneities due to changes in the observers or observational criteria (Pallé and Butler, 2002b; Qian et al., 2006).

Moreover, series of observed TCC (in oktas) were taken from SL09, where more details on the original data can be consulted. These series were originally obtained from the Spanish Agencia Estatal de Meteorologia (AEMET). The data set consists of daily and monthly series of homogeneous TCC records for the Iberian Peninsula covering the period 1961-2004, including data for the previously mentioned 39 stations. These TCC series have been updated from 2005 to 2010 by using the daily average from 3-daily observations taken at 07:00, 13:00 and 18:00 UTC as in SL09, and afterwards the averages have been translated into monthly values. Finally, the TCC series have been converted to percentages by multiplying the oktas by 12.5 . Equally, the monthly frequencies of cloudless and overcast days were computed using the daily series in order to cover the 1961-2010 period.

Consequently, the final monthly TCC dataset analyzed in the present study consists of 39 series over Spain (Fig. 1a, Table 2), with most of the series available since the early 1900s (Figure $1 \mathrm{~b}$ ) and including at least $100 \mathrm{yr}$ of data during the whole 1865-2010 period. For some of the stations, a composite series was generated by using data from more than 
Table 2. Details of the 39 Spanish stations with TCC series considered in this study.

\begin{tabular}{|c|c|c|c|c|c|c|}
\hline ID & Station & Long. $\left(^{\circ}\right)$ & Lat. $\left(^{\circ}\right)$ & Period & Gaps (\%) & Region \\
\hline 1 & Albacete & -1.86 & 38.95 & 1866-2007 & 7.7 & $\mathrm{CS}$ \\
\hline 2 & Alicante & -0.49 & 38.37 & 1866-2007 & 0.9 & $\mathrm{CS}$ \\
\hline 3 & Almería & -2.39 & 36.84 & 1884-2007 & 20.0 & $\mathrm{CS}$ \\
\hline 4 & Badajoz & -6.83 & 38.88 & 1886-2007 & 2.6 & $\mathrm{CW}$ \\
\hline 5 & Barcelona & 2.08 & 41.30 & 1886-2007 & 0.5 & $\mathrm{NE}$ \\
\hline 6 & Bilbao & -2.91 & 43.30 & 1886-2007 & 27.3 & $\mathrm{~N}$ \\
\hline 7 & Burgos & -3.70 & 42.34 & 1886-2007 & 11.6 & $\mathrm{CW}$ \\
\hline 8 & Cáceres & -6.34 & 39.47 & 1882-2007 & 17.3 & $\mathrm{CW}$ \\
\hline 9 & Castellón & -0.02 & 39.95 & 1911-2007 & 10.0 & $\mathrm{CS}$ \\
\hline 10 & Ciudad Real & -3.92 & 38.99 & 1866-2007 & 20.2 & CS \\
\hline 11 & Córdoba & -4.85 & 37.84 & 1912-2007 & 9.2 & $\mathrm{CS}$ \\
\hline 12 & Coruña, La & -8.38 & 43.30 & 1866-2007 & 1.9 & $\mathrm{CW}$ \\
\hline 13 & Cuenca & -2.14 & 40.07 & 1908-2007 & 14.3 & $\mathrm{CS}$ \\
\hline 14 & Gerona & 2.76 & 41.90 & 1884-2007 & 29.2 & $\mathrm{NE}$ \\
\hline 15 & Granada & -3.78 & 37.19 & 1866-2007 & 13.8 & $\mathrm{CS}$ \\
\hline 16 & Huesca & -0.33 & 42.08 & 1866-2007 & 20.7 & $\mathrm{CW}$ \\
\hline 17 & León & -5.65 & 42.59 & 1866-2007 & 28.6 & $\mathrm{CW}$ \\
\hline 18 & Lérida & 0.60 & 41.63 & 1881-2007 & 46.0 & $\mathrm{NE}$ \\
\hline 19 & Logroño & -2.33 & 42.45 & 1881-2007 & 21.7 & $\mathrm{~N}$ \\
\hline 20 & Madrid & -3.68 & 40.41 & 1866-2007 & 2.3 & $\mathrm{CW}$ \\
\hline 21 & Málaga & -4.49 & 36.67 & 1878-2007 & 6.6 & CS \\
\hline 22 & Murcia & -0.80 & 37.79 & 1865-2007 & 7.1 & $\mathrm{CS}$ \\
\hline 23 & Orense & -7.86 & 42.33 & 1887-2007 & 40.8 & $\mathrm{CW}$ \\
\hline 24 & Oviedo & -5.87 & 43.35 & 1865-2007 & 22.4 & $\mathrm{~N}$ \\
\hline 25 & Pamplona & -1.64 & 42.77 & 1881-2007 & 7.3 & $\mathrm{~N}$ \\
\hline 26 & Pontevedra & -8.62 & 42.44 & 1881-2007 & 21.0 & $\mathrm{CW}$ \\
\hline 27 & Salamanca & -5.50 & 40.95 & 1866-2007 & 2.3 & $\mathrm{CW}$ \\
\hline 28 & San Sebastián & -2.04 & 43.31 & 1878-2007 & 21.6 & $\mathrm{~N}$ \\
\hline 29 & Santander & -3.80 & 43.49 & 1878-2007 & 14.8 & $\mathrm{~N}$ \\
\hline 30 & Santiago de Compostela & -8.43 & 42.90 & 1865-2007 & 8.4 & $\mathrm{CW}$ \\
\hline 31 & Sevilla & -5.90 & 37.42 & 1866-2007 & 3.3 & CS \\
\hline 32 & Soria & -2.47 & 41.77 & 1866-2007 & 11.4 & $\mathrm{CW}$ \\
\hline 33 & Tarragona & 1.24 & 41.12 & 1913-2007 & 16.7 & $\mathrm{NE}$ \\
\hline 34 & Teruel & -1.12 & 40.35 & 1878-2007 & 25.5 & $\mathrm{CS}$ \\
\hline 35 & Toledo & -4.05 & 39.88 & 1909-2007 & 3.2 & $\mathrm{CS}$ \\
\hline 36 & Valencia & -0.38 & 39.48 & 1865-2007 & 2.6 & CS \\
\hline 37 & Valladolid & -4.77 & 41.65 & 1866-2007 & 0.9 & $\mathrm{CW}$ \\
\hline 38 & Zamora & -5.73 & 41.52 & 1910-2007 & 19.9 & $\mathrm{CW}$ \\
\hline 39 & Zaragoza & -1.01 & 41.66 & 1866-2007 & 8.7 & $\mathrm{NE}$ \\
\hline
\end{tabular}

one meteorological observatory, mainly due to relocations of the stations.

\subsection{Estimation of the TCC since the latter third of 19th century}

Biel (1963) proposed a simple method to estimate monthly TCC (in \%) by using only the frequencies of cloudless and overcast days in a given period. Thus, a so-called Parameter of Cloudiness (PC) (Parámetro de Nubosidad in Spanish) was defined as

$\mathrm{PC}=50+50 \cdot((O-C) / N)$ where $\mathrm{PC}$ is the estimated TCC in \%,O and $C$ are the number of overcast and cloudless days, respectively, and $N$ is the number of days in a given period (month, season, year). For each of the 39 series that span the period 1865-2010 described in Sect. 3.1, the monthly PC values are obtained using Eq. (1) and the number of cloudless and overcast days.

In order to check the suitability of the PC to estimate TCC at interannual and decadal scales, both variables are compared for the subperiod 1961-2004, which is the period when both datasets are available and have been previously checked for inhomogeneities (SL09). First, the monthly anomalies (obtained as differences to the 1971-2000 mean) of TCC and PC were calculated for each one of the 39 series. Mean 
a

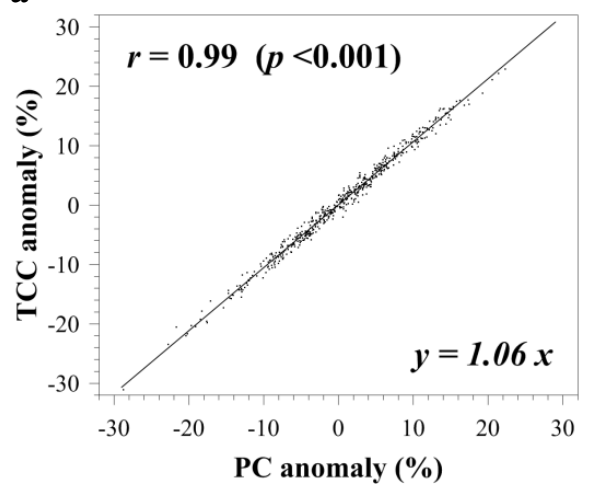

b

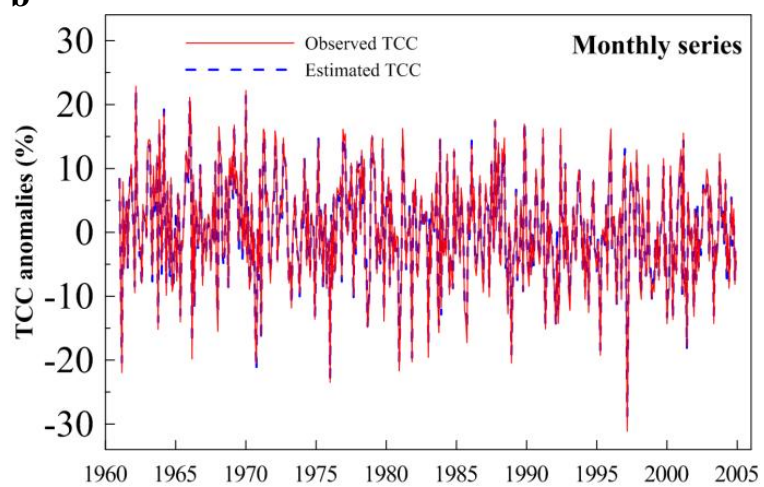

Fig. 2. (a) Scatterplot of the mean monthly anomalies for the observed TCC against the estimated TCC (i.e. parameter of cloudiness, PC) in Spain for the 1961-2004 period. The best fit line is indicated in the plot, together with the linear regression equation and correlation coefficient. (b) Time evolution of the mean monthly anomaly series in Spain of observed and estimated TCC during the 1961-2004 period. The anomalies are expressed as differences from the 1971-2000 mean.

monthly series for the whole of Spain were computed by averaging these 39 anomaly time series. Then, a linear regression is used to estimate the relationship between TCC (dependent variable) and PC (independent variable). The correlation coefficient between both time series is highly significant $(r=0.99, \alpha<0.001)$, and the linear regression equation gives an excellent fit to the data (Fig. 2a). Figure 2b shows that observed and estimated TCC have an excellent agreement on monthly basis during the whole period, resulting in a root mean squared error (RMS) of only $1.01 \%$ between the estimated and observed TCC anomalies.

In conclusion, as Biel (1963) pointed out half a century ago, the $\mathrm{PC}$ has proven to be an excellent measure to estimate the variability of TCC in Spain. Similar agreement between the observed and estimated TCC, using only cloudless and overcast days, has been obtained recently in Poland (Lewik et al., 2010). In conclusion, for the following sections the PC series during the 1865-2010 period are used, and named as estimated TCC in order to distinguish it from the observed TCC series, originally measured in oktas, and only available after the 1960s.

\subsection{Homogenization}

The homogeneity of each of the 39 estimated TCC series was checked by means of the Standard Normal Homogeneity Test (SNHT, Alexanderson and Moberg, 1997). The test was applied with the a priori assumption of non-existence of any homogenous reference series and consists in testing each one of the 39 series against other series, normally in subgroups of preferentially the 5-10 highest correlated series. The tests confirm that only 8 series $(20.5 \%$ of the total) can be considered homogeneous during the whole period. When a break is identified in the estimated TCC series, a reference series used to estimate the monthly adjustments is constructed by averaging the 5-10 highest correlated series, in the most confident 1961-2004 period, that prove to be homogeneous. On the other hand, most of detected and corrected breaks are due to slight inhomogeneities in a subperiod of the series and show a random pattern. Consequently, only small biases are found between the adjusted and original series, and there is only a slight tendency towards higher values of about $+0.4 \%$ in the homogenized annual mean series. After the homogenization, all gaps between the first available year of each series and December 2010 were filled with estimates based on the most correlated reference series. Table 2 shows the percentage of gaps filled in each series. After filling the gaps, Figure $1 \mathrm{~b}$ shows that only 4 series have records in 1865 , more than $50 \%$ are available after 1866 , and $100 \%$ since 1913 . Consequently, the following analysis will be limited to the period 1866-2010, although with greater confidence for the subperiod 1913-2010.

Finally, Fig. 3 shows the mean annual estimated TCC homogenized series obtained by averaging the 39 stations during the whole 1866-2010 period. Figure 3 also shows the mean annual estimated TCC series for the original series, a curve divided into the 1866-1960 and 1961-2010 subperiods that are derived from overcast/cloudless days and "true TCC" observations in oktas, respectively. It is clear from this figure that the estimation of the TCC by using only cloudless and overcast conditions before the 1960s and the derivation of these sky conditions from the "true TCC" after the 1960s do not introduce a bias in the whole estimated TCC series. Equally, it is obvious that the homogenization step does not introduce any artificial trends in the series.

\subsection{Regionalization and trend analysis}

In order to study the trends of TCC in different regions of Spain with similar decadal variability, a regionalization was performed by means of an s-mode principal component analysis (PCA) (e.g. Sanchez-Lorenzo et al., 2007). The analysis 


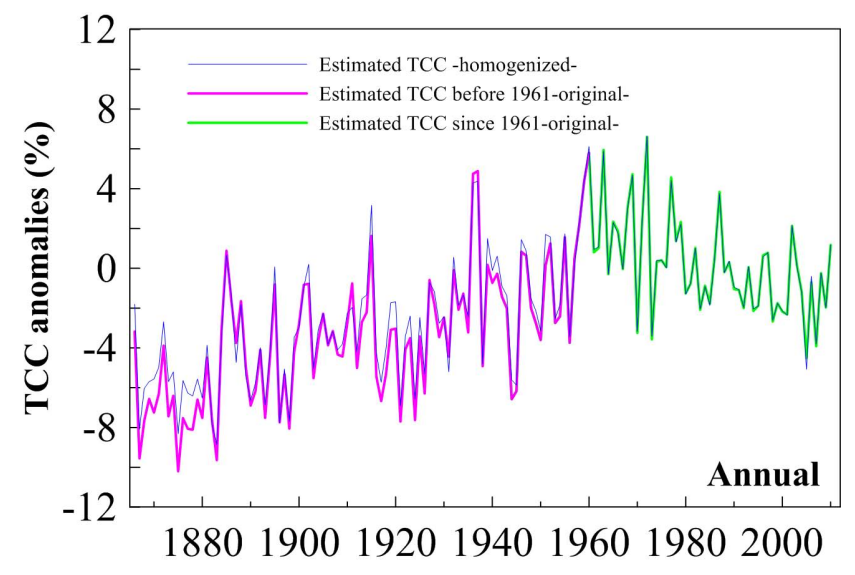

Fig. 3. Time evolution of the mean annual series in Spain for the estimated TCC homogenized series over the 1866-2010 period and for the original estimated TCC series divided in the 1866-1960 and 1961-2010 subperiods. The anomalies are expressed as differences from the 1971-2000 mean.

was applied to the 39 series, which correspond to the number of original variables, but considering all 12 months of the year and using the series of monthly anomalies for each of these series (obtained as differences to the 1971-2000 mean for each month). The PCA was calculated starting from a correlation matrix and using the data of the period 19132010 , which is complete without missing values, comprising 1164 rows ( $97 \mathrm{yr} \times 12$ months) for each of the 39 original variables. The use of all months of the year is justified in order to obtain more robust statistical results, and produces only one representative regionalization of the whole year, which avoids the confusion that occurs if different regions are defined for each month or season.

The results of the PCA show that 4 empirical orthogonal functions (EOF) account for more variance than the original variables (eigenvalues $>1$ ) and explain more than $70 \%$ of the total variance. These EOF were rotated (VARIMAX rotation) in order to redistribute the variance into the components and to obtain physically meaningful patterns (von Storch and Zwiers, 1999). Figure 4 shows the spatial distributions of the loadings of each EOF, which clearly identify the following regions: (a) the central-south (CS) region for the EOF-1, (b) the central-west $(\mathrm{CW})$ region for the EOF2, (c) the north $(\mathrm{N})$ region for the EOF-3, (d) the north-east (NE) region for the EOF-4. Each station was assigned into one of these regions according to the maximum loading rule (Sanchez-Lorenzo et al., 2007). In Table 2 the indication of the stations assigned to each region is shown in the rightmost column.

After the regionalization, annual and seasonal series representative of the whole Spain (individual regions) were computed as an arithmetic mean of the 39 monthly anomalies series (available series in each region). Due to the low number of stations with records before 1913, regional mean series
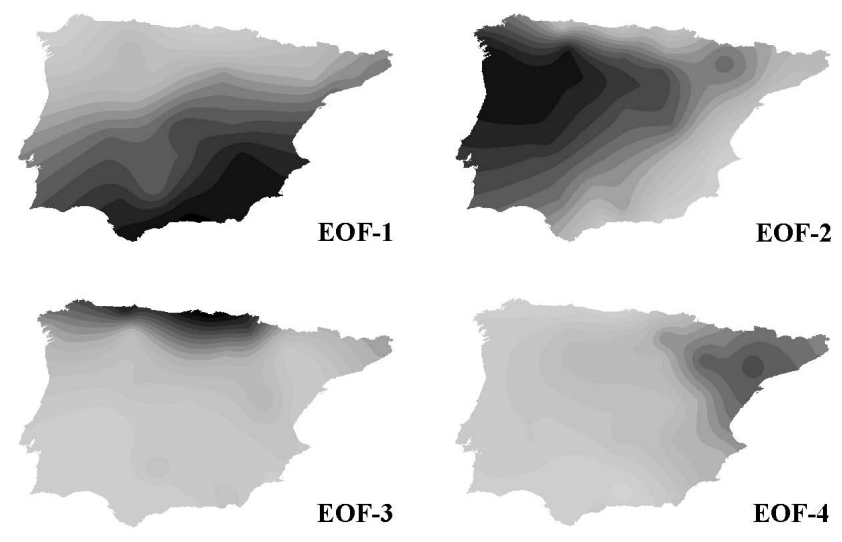

$\begin{array}{llllllll}0.1 & 0.2 & 0.3 & 0.4 & 0.5 & 0.6 & 0.7 & 0.8\end{array}$

Fig. 4. First four rotated EOF obtained from the PCA applied to the estimated TCC monthly anomaly series over the 1913-2010 period. The maps show the isopleths of the loadings of the EOFs.

are only constructed for the 1913-2010 period, although for the mean series of Spain the whole 1866-2010 period is provided. The seasons are defined as spring (MAM), summer (JJA), autumn (SON), and winter (DJF). The use of the composite series enhances the signal-to-noise ratio, which permits a better identification of long-term trends, as well as reduces the noise introduced by local features and remaining inhomogeneities. Due to the strong spatial autocorrelation in the TCC series, with the subset of 39 series available in this study it is possible to capture the same variability as using the grid data generated by SL09 with 69 series over the Iberian Peninsula, i.e. correlation coefficients between 0.96 and 0.99 for seasonal mean series (not shown). Consequently, the dataset used here can perfectly capture the interannual and decadal variability of the whole Iberian Peninsula.

The linear trends of the series were calculated by means of least squares linear fitting and their significance estimated by the Mann-Kendall nonparametric test (Sanchez-Lorenzo et al., 2007). The linear trends are applied over the 18662010 (1913-2010) period, as well as different subperiods, for the mean Spanish (regional) series. Also, all the time series are smoothed with a 13-yr Gaussian low-pass filter (hereafter referred as 13GLPF), which improves the visualization of the long-term variability when plotted together. The 13GLPF only consider the values on one side at the start and end of the series in order to filter the full period.

\section{Decadal variability and trends of the estimated TCC in Spain}

Figure 5 shows the mean annual and seasonal estimated TCC series in Spain, together with the 13GLPF, during the period 1866-2010. The linear trends for these estimated TCC series, 


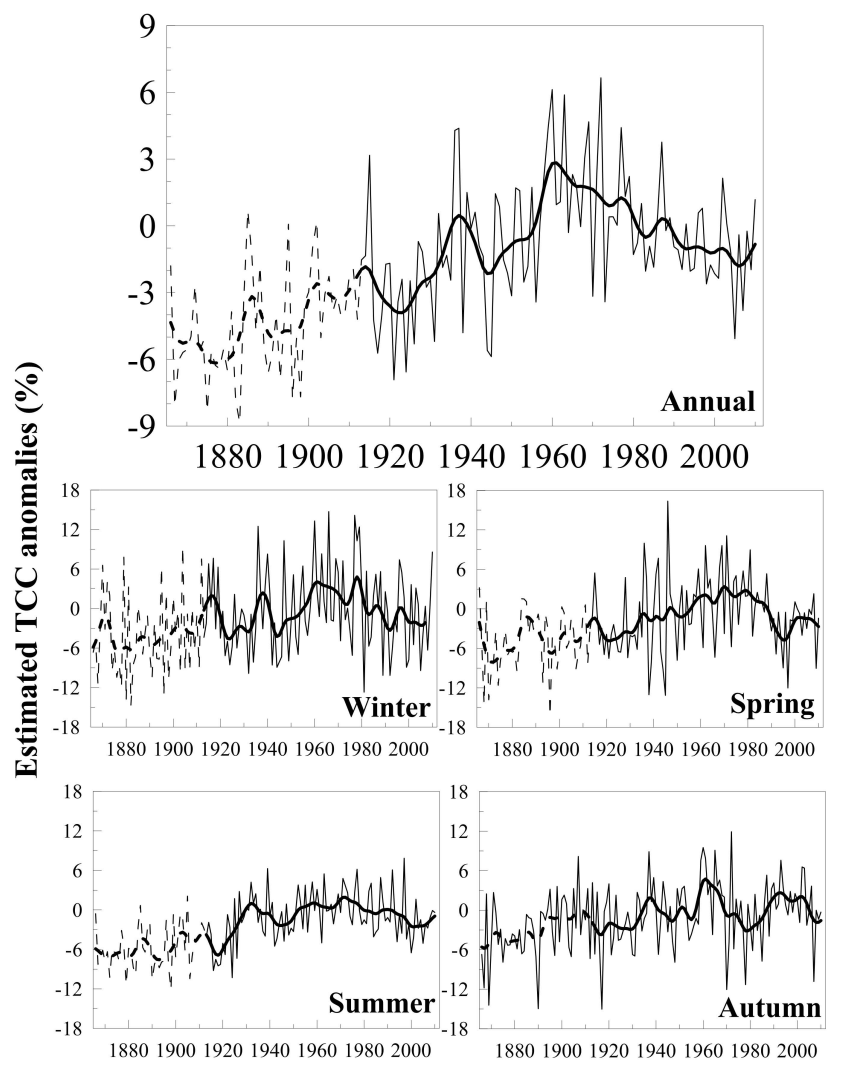

Fig. 5. Mean annual and seasonal estimated TCC (\%) series (thin lines) from 1866 to 2010 in Spain, plotted together with a 13-year Gaussian low-pass filter (thick line). The series are expressed as anomalies from the 1971-2000 mean. Dashed lines are used before 1913 to indicate the lower number of series available before this year.

calculated over the whole available period and different subperiods, are summarized in Table 3.

The mean annual estimated TCC series shows a tendency towards an increase from the beginning to the early 1960s, although the decadal variability highlights periods of a decrease in the 1870s, 1890s, 1920s and 1940s. After the 1960s, the series shows a decrease until the mid-2000s in line with the reported trends by SL09 during the period 1961-2004. On the other hand, in the final years (2005-2010) there is a stabilization or slight increase of the TCC, which points to a reversal in the negative trend since the 1960s, although the number of years is still insufficient to establish if a new increasing period in TCC is starting over Spain. The linear trend, estimated over the 1866-2010 period, exhibits a significant increase with a rate of $+0.44 \%$ per decade or about $6 \%$ over the whole $144-y r$ period. If the analyzed period is limited to the most confident 1913-2010 period, the significant increase is lower, with a rate of $+0.22 \%$ per decade or about $2 \%$ over the whole $97-y r$ period. When this most confident 1913-2010 period is subdivided in the 1913-1960 and 1961-2010 subperiods, the linear trends show a significant
Table 3. Annual and seasonal trends for the estimated TCC mean series in Spain over the 1866-2010 period and different subperiods. The values are expressed as \% per decade. Bold, italic and regular numbers indicate trends with significance level higher than $99 \%$, $95 \%$ and $90 \%$, respectively. For lower levels of significance only the sign of the trend is indicated.

\begin{tabular}{lcccc}
\hline Periods & $1866-2010$ & $1913-2010$ & $1913-1960$ & $1961-2010$ \\
\hline Annual & $\mathbf{+ 0 . 4 4} \pm \mathbf{0 . 0 5}$ & $+0.22 \pm 0.09$ & $\mathbf{+ 0 . 9 1} \pm \mathbf{0 . 2 9}$ & $-\mathbf{0 . 8 0} \pm \mathbf{0 . 2 1}$ \\
Winter & $\mathbf{+ 0 . 4 0} \pm \mathbf{0 . 1 3}$ & + & + & $-1.12 \pm 0.65$ \\
Spring & $\mathbf{+ 0 . 4 5} \pm \mathbf{0 . 1 0}$ & + & + & $-\mathbf{1 . 2 8} \pm \mathbf{0 . 4 5}$ \\
Summer & $\mathbf{+ 0 . 5 3} \pm \mathbf{0 . 0 7}$ & + & $\mathbf{+ 1 . 3 4} \pm \mathbf{0 . 3 6}$ & $-0.67 \pm 0.31$ \\
Autumn & $\mathbf{+ 0 . 3 8} \pm \mathbf{0 . 0 9}$ & $+0.28 \pm 0.17$ & + & - \\
\hline
\end{tabular}

increase of $+0.91 \%$ per decade $(+4.3 \%$ over the $47-\mathrm{yr}$ subperiod) and decrease of $-0.80 \%$ per decade $(-3.9 \%$ over the 49-yr subperiod), respectively.

On a seasonal basis, the estimated TCC mean series show similar temporal patterns and trends as the annual series previously described, although the highest rate of significant increase is found in summer ( $+0.53 \%$ per decade) and spring $(+0.45 \%$ per decade) during the whole $1866-2010$ period. If the trends are limited to the most confident 1913-2010 period, the most remarkable feature is that only in autumn a significant trend $(+0.28 \%$ per decade $)$ is present. On the other hand, the strongest rate found in summer is mainly due to a sharp increase between the 1910s and 1930s, which results in a positive trend of $+1.34 \%$ per decade during the $1913-$ 1960 subperiod. For the subperiod 1961-2010, the decrease in the estimated TCC is more obvious in spring $(-1.28 \%$ per decade), followed by winter $(-1.12 \%$ per decade) and summer $(-0.67 \%$ per decade). Overall, it is interesting to note that the break point observed in the early 1960 s for the annual series is only visible in the winter and autumn seasons, whereas in summer and spring the transition from the increase to the decrease is set around the mid-late 1970s.

Figure 6 shows the mean annual series of the estimated TCC for the four regions defined by means of a PCA in Spain, together with the 13GLPF, during the period 19132010. The linear trends, calculated over the whole 19132010 period and the 1913-1960 and 1961-2010 subperiods, are summarized in Table 4.

The mean annual series for the CS region show the most similar temporal pattern to that covering the whole Spain, as expected due to the larger fraction of stations localized in this region. The trend analysis reveals a significant increase of $+0.27 \%$ per decade over the whole 1913-2010 period, as well a significant increase (decrease) of $+1.11 \%$ per decade ( $-0.89 \%$ per decade) in the 1913-1960 (1961-2010) subperiod, which are values slightly higher than for the mean series for the whole Spain. Equally, the CW regional series shows a similar decadal variability during the analyzed period, although the increase before the 1960s is more moderate than in the previously described time series. Consequently, the linear trend over the whole 1913-2010 period is positive but not 


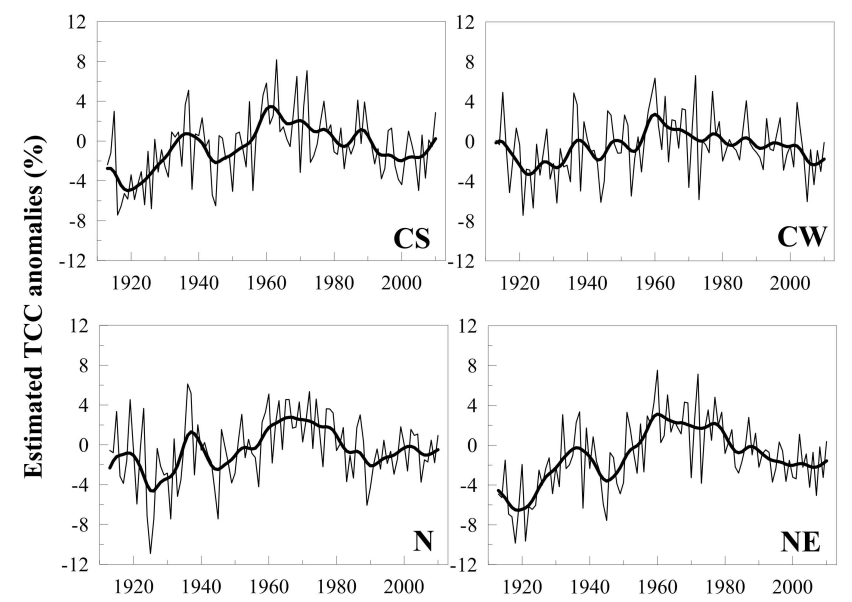

Fig. 6. As in Fig. 5, but for the annual mean estimated TCC (\%) series of the four regions defined by means of a PCA applied to the 39 estimated TCC series. The series are only plotted for the subperiod 1913-2010 when all series are available.

significant, despite that it is significant if the analyzed period is restricted to the $1913-1960(+0.63 \%$ per decade $)$ and 1961-2010 subperiods ( $-0.59 \%$ per decade). On the other hand, the $\mathrm{N}$ regional series presents the most relevant differences, as it starts with a stronger decrease during the 1920s, reaching a clear absolute minimum in 1925 . Furthermore, the tendency towards a general decrease in the estimated TCC starts in the mid-1970s with a gradual change, that is later and less obvious than in the other regional series. In this region, neither the positive trend over the whole 1913-2010 period nor 1913-1960 subperiod are statistically significant, although for the 1961-2010 a significant decrease of $-0.84 \%$ per decade is found, possibly due to the lower variability that is visible in the series since the second half of the 20th century. Finally, the NE regional mean series provides a decadal variability very similar to the mean series over Spain, although with larger decadal changes, which implies a stronger increase of $+0.40 \%$ per decade during the whole 1913-2010 period. Equally, both the linear trends for the 1913-1960 (+1.64\% per decade) and $1961-2010$ ( $-1.09 \%$ per decade $)$ subperiods present higher trend values than the mean series over Spain and the other regions.

With respect to the seasonal series, only the most remarkable characteristics, based on the linear trends (Table 4), are described here, in order to reduce the redundant information that would happen if all time evolutions of mean seasonal series were described. For the CS and NE regional series, which show the strongest increase in the annual mean series over the whole 1913-2010 period, the most remarkable feature is the tendency towards highest rates of significant increase (decrease) in the summertime, i.e. spring and summer seasons, during the 1913-1960 (1961-2010) subperiod, ranging between $+1.16 \%$ and $+1.93 \%$ per decade $(-0.92 \%$ and $-1.61 \%$ per decade). On the other hand, for the CW
Table 4. As in Table 3, but for the mean series of the four regions defined in Spain.

\begin{tabular}{|c|c|c|c|}
\hline Periods & $1913-2010$ & $1913-1960$ & $1961-2010$ \\
\hline \multicolumn{4}{|c|}{ EOF-1, Region CS } \\
\hline Annual & $+0.27 \pm 0.11$ & $+1.11 \pm 0.32$ & $-\mathbf{0 . 8 9} \pm \mathbf{0 . 2 5}$ \\
\hline Winter & + & + & - \\
\hline Spring & $+0.30 \pm 0.20$ & $+\mathbf{1 . 5 0} \pm \mathbf{0 . 5 8}$ & $-1.38 \pm 0.46$ \\
\hline Summer & + & $+1.16 \pm 0.47$ & $-\mathbf{0 . 9 2} \pm \mathbf{0 . 3 0}$ \\
\hline Autumn & + & $+0.89 \pm 0.46$ & - \\
\hline \multicolumn{4}{|c|}{ EOF-2, Region CW } \\
\hline Annual & + & $+0.63 \pm 0.33$ & $-0.59 \pm 0.25$ \\
\hline Winter & - & - & - \\
\hline Spring & - & + & $-1.04 \pm 0.53$ \\
\hline Summer & $+0.33 \pm 0.15$ & $+1.36 \pm 0.41$ & - \\
\hline Autumn & + & + & - \\
\hline \multicolumn{4}{|c|}{ EOF-3, Region $N$} \\
\hline Annual & + & + & $-0.84 \pm 0.23$ \\
\hline Winter & - & - & $-1.26 \pm 0.61$ \\
\hline Spring & + & + & $-1.49 \pm 0.52$ \\
\hline Summer & $+0.39 \pm 0.15$ & $+1.24 \pm 0.44$ & - \\
\hline Autumn & + & + & - \\
\hline \multicolumn{4}{|c|}{ EOF-4, Region NE } \\
\hline Annual & $+0.40 \pm 0.12$ & $+1.64 \pm 0.32$ & $-1.09 \pm 0.22$ \\
\hline Winter & $+0.42 \pm 0.20$ & $+0.98 \pm 0.55$ & - \\
\hline Spring & $+0.44 \pm 0.19$ & $+1.85 \pm 0.53$ & $-1.41 \pm 0.47$ \\
\hline Summer & + & $+1.93 \pm 0.41$ & $-1.61 \pm 0.34$ \\
\hline Autumn & $+0.52 \pm 0.18$ & $+1.69 \pm 0.49$ & - \\
\hline
\end{tabular}

and $\mathrm{N}$ regions, the summer trends are positive and significant over the 1913-2010 period, mainly due to the strong increase observed during the 1913-1960 subperiod, although the trends were non-significant on an annual basis. In winter, the only significant trends over the whole period and 19131960 subperiod are detected in the NE region, with a rate of $+0.42 \%$ and $+0.98 \%$ per decade, respectively. Nevertheless, if the trends analyses are limited to the second subperiod, the only significant value is observed in the $\mathrm{N}$ region $(-1.26 \%$ per decade).

\section{Discussion and conclusions}

In this work we have first reviewed the studies reporting trends in cloudiness before the second half of the 20th century, highlighting a widespread increase of TCC detected during the 20th century over most of the studied areas.

Secondly, an increase of the TCC is confirmed in Spain since the second half of the 19th century, especially from the early 20 th century to the 1960 s/70s during the summertime, followed by a decrease up to the present. When regional series are analyzed, similar features are found for the 
central-southern and north-eastern areas of Spain, and the trends are more moderate in the western and northern sectors. Overall, an increase of about $6 \%$ in TCC is observed in Spain during the period 1866-2010, in line with the overall rates reported for Europe (Henderson-Sellers, 1986a, 1992) and the increase for the western area of the Alpine region (Brunetti et al., 2009).

However, the time evolution for the whole of Europe reported by Henderson-Sellers (1992) shows that this positive trend in the annual series is mainly due to an increase during the 1950s-1970s subperiod. This is not the case over Spain, which shows a tendency towards an increase from the late 19th century to the 1960s. Moreover, HendersonSellers (1986a) reported a significant decrease in the only Spanish series (i.e. the station Granada) included in her study, which she had available for the 1908-1953 period. Nevertheless, it is worth noticing that if the Granada series is analyzed independently from our dataset, the linear trend for the $1908-1953$ period is also significant and negative $(-1.6 \%$ per decade) in agreement with Henderson-Sellers (1986a). Equally, the reported increase in TCC at a northern station of Spain (Curto et al., 2009), which is not included in the current study, is in line with our findings, although the rate of increase for this specific station is considerably higher than the one provided in our results. This fact, together with the decreasing trend found at individual stations, such as in southern Spain (i.e. Granada), highlights the importance of the temporal homogenization of the datasets, as well as the suitability of the composite mean series in order to avoid local peculiarities and remaining inhomogeneities in the time series.

The decadal increases in the TCC during the last century have been worldwide related to an increase in precipitation and reduction in diurnal temperature range (DTR) (Karl et al., 1993; Dai et al., 1997, 1999). Equally, the evidence of an increase (decrease) in TCC from the 1950s to the 1980s (1980s to the 2000s) has been suggested as a contributing factor of the widespread decrease or global dimming (increase or brightening) in surface solar radiation observed around the same period. Nevertheless, changes in the transmissivity of the Earth's atmosphere, as consequence of the trends in the aerosol anthropogenic emissions since the mid20 th century, is considered the most likely cause of the dimming/brightening periods (Wild, 2009, 2012). On the other hand, for Spain a systematic assessment of the DTR trends for the whole 20th century is still lacking, to our knowledge. Nevertheless, the TCC trends reported here are in line with the generalized increase (decrease) in the number of rainy days during the first (second) half of the 20th century in Spain (Gallego et al., 2011). Regarding the observed trends since the 1950s, a large discrepancy between sunshine duration and TCC has been shown, which suggests that the most likely cause of the dimming/brightening in Spain is also dominated by aerosol effects (Sanchez-Lorenzo et al., 2009).
In conclusion, from the review of the previous studies, it seems very plausible that TCC has been enhanced during the 20th century over most of the World. This increase in TCC is also visible in Spain using a homogeneous data set covering the 1866-2010 period, although a decreasing trend is found since the 1960s.

The important role of clouds in the Earth's system, and the intriguing trends reported for TCC during the last century, which have not been fully explained, should encourage a future compilation of the long-term series of traditional cloudiness observations at global scale. If real, the observed trends in TCC since the late 19th century will help to improve our knowledge on current anthropogenic climate change, and reduce the uncertainties in future climate scenarios. Equally, cloud cover variations have recently been proven to be an excellent variable to be related with dendrochronological data, and consequently can be helpful to improve climate reconstructions over the last millennium (e.g. Young et al., 2010; Gagen et al., 2011).

Acknowledgements. This research was supported by the Spanish Ministry of Science and Innovation project NUCLIERSOL (CGL2010-18546). The first author was supported by a postdoctoral fellowship from the "Comissionat per a Universitats $i$ Recerca del Departament d'Innovació, Universitats i Empresa de la Generalitat de Catalunya" (2009 BP-A 00035). We thank the Spanish Agencia Estatal de Meteorologia (AEMET) for providing the total cloud cover series, as well as its Regional Meteorological Centre in Catalonia to facilitate the access to the archive to digitize the monthly summaries of cloudless and overcast days. We also thank Elena Guinaldo who collected and digitized the data from the archives, Javier Martin Vide for the support to our work, and Sonia Fernández-Montes for helpful comments.

Edited by: P. Brohan

\section{References}

Alexandersson, H. and Moberg, A.: Homogenization of Swedish temperature data, Part I: homogeneity test for linear trends, Int. J. Climatol., 13, 191-201, 1997.

Angell, J. K.: Variations in United States cloudiness and sunshine duration between 1950 and the drought year of 1988, J. Climate, 3, 296-308, 1990.

Auchmann, R., Brönnimann, S., Breda, L., Bühler, M., Spadin, R., and Stickler, A.: Extreme climate, not extreme weather: the summer of 1816 in Geneva, Switzerland, Clim. Past, 8, 325-335, doi:10.5194/cp-8-325-2012, 2012.

Bajuk, L. J. and Leovy, C. B.: Are there real interdecadal variations in marine low clouds?, J. Climate, 11, 2910-2921, 1998.

Bedacht, E., Gulev, S. K., and Macke, A.: Intercomparison of global cloud fields over oceans from the VOS observations and NCEP/NCAR reanalysis, Int. J. Climatol., 27, 1707-1719, 2007.

Biel, A.: Nubosidad e insolación, Boletín Mensual Climatológico, Servicio Meteorológico Nacional, Madrid, 2-9, 1963. 
Biggs, T. W., Scott, C. A., Rajagopalan, B., and Turral, H. N.: Trends in solar radiation due to clouds and aerosols, southern India, 1952-1997, Int. J. Climatol., 27, 1505-1518, 2007.

Brönnimann, S., Annis, J., Dann, W., Ewen, T., Grant, A. N., Griesser, T., Krähenmann, S., Mohr, C., Scherer, M., and Vogler, C.: A guide for digitising manuscript climate data, Clim. Past, 2, 137-144, doi:10.5194/cp-2-137-2006, 2006.

Brunetti, M., Lentini, G., Maugeri, M., Nanni, T., Auer, I., Böhm, R., and Schöner, W.: Climate variability and change in the Greater Alpine Region over the last two centuries based on multivariable analysis, Int. J. Climatol., 19, 2197-2225, 2009.

Calbó, J. and Sanchez-Lorenzo, A.: Cloudiness climatology in the Iberian Peninsula from three global gridded datasets (ISCCP, CRU TS 2.1, ERA-40), Theor. Appl. Climatol., 96, 105-115, 2009.

Cermak, J., Wild, M., Knutti, R., Mishchenko, M. I., and Heidinger, A. K.: Consistency of global satellite-derived aerosol and cloud data sets with recent brightening observations, Geophys. Res. Lett., 37, L21704, doi:10.1029/2010GL044632, 2010.

Changnon, S. A.: Midwestern Cloud, Sunshine and Temperature Trends since 1901: Possible Evidence of Jet Contrail Effects, J. Appl. Meteorol., 20, 496-508, 1981.

Croke, M. S., Cess, R. D., and Hameed, S.: Regional Cloud Cover Change Associated with Global Climate Change: Case Studies for Three Regions of the United States, J. Climate, 12, 21282134, 1999.

Curto, J., Also, E., Pallé, E., and Solé, G.: Sunshine and synoptic cloud observations at Ebro Observatory, 1910-2006, Int. J. Climatol., 29, 2183-2190, 2009.

Dai, A., Del Genio, A. D., and Fung, I. Y.: Clouds, precipitation, and temperature range, Nature, 386, 665-666, 1997.

Dai, A., Trenberth, K. E., and Karl, T. R.: Effects of clouds, soil moisture, precipitation, and water papor on diurnal temperature range, J. Climate, 12, 2451-2473, 1999.

Dai, A., Karl, T. R., Sun, B., and Trenberth, K. E.: Recent trends in cloudiness over the United States: a tale of monitoring inadequacies, B. Am. Meteorol. Soc., 87, 597-606, 2006.

Eastman, R., Warren, S., and Hahn, C.: Variations in cloud cover and cloud types over the ocean from surface observations, 19542008, J. Climate, 24, 5914-5934, 2011.

Elms, J. D., Woodruff, S. D., Worley, S. J., and Hanson, C.: Digitizing Historical Records for the Comprehensive OceanAtmosphere Data Set (COADS), Earth Syst. Monitor, 4, 4-10, 1993.

Evan, A. T., Heidinger, A. K., and Vimont, D.: Arguments against a physical long-term in global ISCCP cloud amounts, Geophys. Res. Lett., 34, L04701, doi:10.1029/2006GL028083, 2007.

Gagen, M., Zorita, E., McCarroll, D., Young, G. H. F., Grudd, H., Jalkanen, R., Loader, N. J., Robertson, I., and Kirchhefer, A.: Cloud response to summer temperatures in Fennoscandia over the last thousand years, Geophys. Res. Lett., 38, L05701, doi:10.1029/2010GL046216, 2011.

Gallego, M. C., Trigo, R. M., Vaquero, J. M., Brunet, M., García, J. A., Sigró, J., and Valente, M. A.: Trends in frequency indices of daily precipitation over the Iberian Peninsula during the last century, J. Geophys. Res., 116, D02109, doi:10.1029/2010JD014255, 2011.

Henderson-Sellers, A.: Cloud changes in a warmer Europe, Climatic Change, 8, 25-52, 1986a.
Henderson-Sellers, A.: Increasing cloud in a warmer world, Climatic Change, 9, 267-309, 1986b.

Henderson-Sellers, A.: North American total cloud amount variations this century, Global Planet. Change, 1, 175-194, 1989.

Henderson-Sellers, A.: Continental cloudiness changes this century, GeoJournal, 27, 255-262, 1992.

Henderson-Sellers, A. and McGuffie, K.: Diagnosis of cloud amount increase from an analogue model of a warming world, Atmósfera, 2, 67-101, 1989.

Houghton, J. T., Jenkins, G. J., and Ephraums, J. J. (Eds.): Climate Change: The IPCC Scientific Assessment, Report prepared for Intergovernmental Panel on Climate Change by Working Group I, Cambridge University Press, Cambridge, UK, New York, NY, USA and Melbourne, Australia, 1990.

Houghton, J. T., Meira Filho, L. G., Callander, B. A., Harris, N., Kattenberg, A., and Maskell, K. (Eds.): Climate Change 1995: The Science of Climate Change, Contribution of WGI to the Second Assessment Report of the Intergovernmental Panel on Climate Change, Cambridge University Press, Cambridge, UK and New York, NY, USA, 1996.

Houghton, J. T., Ding, Y. Griggs, D. J., Noguer, M., van der Linden, P. J., Dai, X., Maskell, K., and Johnson, C. A. (Eds.): Climate Change 2001: The Scientific Basis, Contribution of Working Group I to the Third Assessment Report of the Intergovernmental Panel on Climate Change, Cambridge University Press, Cambridge, UK and New York, NY, USA, 2001.

Ishii, M., Shouji, A., Sugimoto, S., and Matsumoto, T.: Objective analyses of sea-surface temperature and marine meteorological variables for the $20^{\text {th }}$ century using ICOADS and the Kobe collection, Int. J. Climatol., 25, 865-879, 2005.

Jones, P. A. and Henderson-Sellers, A.: Historical records of cloudiness and sunshine in Australia, J. Climate, 5, 260-267, 1992.

Jovanovic, B., Collins, D., Braganza, K., Jakob, D., and Jones, D. A.: A high-quality monthly total cloud amount dataset for Australia, Climatic Change, 108, 485-517, 2011.

Kaiser, D. P.: Decreasing cloudiness over China: An updated analysis examining additional variables, Geophys. Res. Lett., 27, 2193-2196, doi:10.1029/2000GL011358, 2000.

Karl, T. R. and Steurer, P. M.: Increased cloudiness in the United States during the first half of the twentieth century: fact or fiction?, Geophys. Res. Lett., 17, 1925-1928, 1990.

Karl, T. R., Knight, R. W., Gallo, K. P., Peterson, T. C., Jones, P. D., Kukla, G., Plummer, N., Razuvayev, V., Lindseay, J., and Charlson, R. J.: A New Perspective on Recent Global Warming: Asymmetric Trends of Daily Maximum and Minimum Temperature, B. Am. Meteorol. Soc., 74, 1007-1023, 1993.

Khlebnikova, E. I. and Sall, I. A.: Peculiarities of climatic changes in cloud cover over the Russian Federation, Russ. Meteorol. Hydrol., 34, 411-417, 2009.

Kruger, A. C.: Trends in cloud cover from 1960 to 2005 over South Africa, Water SA, 33, 603-608, 2007.

Lewik, P., Matuszko, D., and Morawska-Horawska, M.: MultiAnnual Variability of Cloudiness and Sunshine Duration in Cracow Between 1826 and 2005, in: The Polish Climate in the European Context: An Historical Overview, edited by: Przybylak, R., Majorowicz, J., Brázdil, R., and Kejan, M., Springer Science + Business Media, 341-353, 2010. 
Mace, G. G., Benson, S., and Kato, S.: Cloud radiative forcing at the Atmospheric Radiation Measurement Program Climate Research Facility: 2. Vertical redistribution of radiant energy by clouds, J. Geophys. Res., 111, D11S91, doi:10.1029/2005JD005922, 2006.

Maugeri, M., Bagnati, Z., Brunetti, M., and Nanni, T.: Trends in Italian total cloud amount, 1951-1996, Geophys. Res. Lett., 28, 4551-4554, doi:10.1029/2001GL013754, 2001.

Matuszko, D.: Cloudiness changes in Cracow in the 20th century, Int. J. Climatol., 23, 975-984, 2003.

McGuffie, K. and Henderson-Sellers, A.: Is Canadian cloudiness increasing?, Atmos. Ocean, 26, 608-633, 1988.

Moberg, A., Alexandersson, H., Bergström, H., and Jones, P.D.: Were southern Swedish summer temperatures before 1860 as warm as measured?, Int. J. Climatol., 23, 1495-1521, 2003.

Norris, J. R.: On trends and possible artifacts in global ocean cloud cover between 1952 and 1995, J. Climate, 12, 1864-1870, 1999.

Norris, J. R.: Multidecadal changes in near-global cloud cover and estimated cloud cover radiative forcing, J. Geophys. Res., 110, D08206, doi:10.1029/2004JD005600, 2005.

Pallé, E. and Butler, C. J.: Sunshine records from Ireland, cloud factors and possible links to solar activity and climate, Int. J. Climatol., 21, 709-729, 2001.

Pallé, E. and Butler, C. J.: The proposed connection between clouds and cosmic rays: cloud behaviour during the past 50-120 years, J. Atmos. Sol.-Ter. Phy., 64, 327-337, 2002a.

Pallé, E. and Butler, C. J.: Comparison between sunshine records and synoptic cloud observations: a case study for Ireland, Phys. Chem. Earth, 27, 405-414, 2002b.

Parungo, F., Boatman, J. F., Sievering, H., and Hicks, B. B.: Trends in global marine cloudiness and anthropogenic sulfur, J. Climate, 23, 434-440, 1994.

Qian, Y., Kaiser, D. P., Leung, L. R., and Xu, M.: More frequent cloud-free sky and less surface solar radiation in China from 1955 to 2000, Geophys. Res. Lett., 33, L01812, doi:10.1029/2005GL024586, 2006.

Randall, D. A., Wood, R. A., Bony, S., Colman, R., Fichefet, T., Fyfe, J., Kattsov, V., Pitman, A., Shukla, J., Srinivasan, J., Stouffer, R. J., Sumi, A., and Taylor, K. E.: Climate Models and Their Evaluation, in: Climate Change 2007: The Physical Science Basis, Contribution of Working Group I to the Fourth Assessment Report of the Intergovernmental Panel on Climate Change, edited by: Solomon, S., Qin, D., Manning, M., Chen, Z., Marquis, M., Averyt, K. B., Tignor, M., and Miller, H. L., Cambridge University Press, Cambridge, UK and New York, NY, USA, 589-662, 2007.

Sanchez-Lorenzo, A. and Wild, M.: Decadal variations in estimated surface solar radiation over Switzerland since the late 19th century, Atmos. Chem. Phys. Discuss., 12, 10815-10843, doi:10.5194/acpd-12-10815-2012, 2012.

Sanchez-Lorenzo, A., Brunetti, M., Calbó, J., and Martin-Vide, J.: Recent spatial and temporal variability and trends of sunshine duration over the Iberian Peninsula from a homogenized dataset, J. Geophys. Res., 112, D20115, doi:10.1029/2007JD008677, 2007.

Sanchez-Lorenzo, A., Calbó, J., Brunetti, M., and Deser, C.: Dimming/brightening over the Iberian Peninsula: Trends in sunshine duration and cloud cover, and their relations with atmospheric circulation, J. Geophys. Res., 114, D00D09, doi:10.1029/2008JD011394, 2009.
Seaver, W. L. and Lee, J. E.: A Statistical Examination of Sky Cover Changes in the Contiguous United States, J. Clim. Appl. Meteorol., 26, 88-95, 1987.

Solomon, S., Qin, D., Manning, M., Chen, Z., Marquis, M., Averyt, K., Tignor, M., and Miller, H. (Eds.): Climate Change 2007: The Physical Science Basis, Contribution of Working Group I to the Fourth Assessment Report of the Intergovernmental Panel on Climate Change, Cambridge University Press, Cambridge, UK and New York, NY, USA, 2007.

Sun, B..: Cloudiness over the contiguous United States: Contemporary changes observed using ground-based and ISCCP D2 data, Geophys. Res. Lett., 30, 1053, doi:10.1029/2002GL015887, 2003.

Sun, B. and Groisman, P. Y.: Cloudiness variations over the former Soviet Union, Int. J. Climatol., 20, 1097-1111, 2000.

Tuomenvirta, H., Alexandersson, H., Drebs, A., Frich, P., and Nordli, P. O.: Trends in Nordic and Arctic temperature extremes and ranges, J. Climate, 13, 977-990, 2000.

Venema, V. K. C., Mestre, O., Aguilar, E., Auer, I., Guijarro, J. A., Domonkos, P., Vertacnik, G., Szentimrey, T., Stepanek, P., Zahradnicek, P., Viarre, J., Müller-Westermeier, G., Lakatos, M., Williams, C. N., Menne, M. J., Lindau, R., Rasol, D., Rustemeier, E., Kolokythas, K., Marinova, T., Andresen, L., Acquaotta, F., Fratianni, S., Cheval, S., Klancar, M., Brunetti, M., Gruber, C., Prohom Duran, M., Likso, T., Esteban, P., and Brandsma, T.: Benchmarking homogenization algorithms for monthly data, Clim. Past, 8, 89-115, doi:10.5194/cp-8-89-2012, 2012.

Von Storch, H. and Zwiers, F. W.: Statistical Analysis in climate research. Cambridge University Press, UK, 1999.

Warren, S. G., Hahn, C. J., London, J., Chervin, R. M., and Jenne, R. L.: Global distribution of total cloud cover and cloud type amounts over the ocean, NCAR Technical Note, TN-317+STR, National Center for Atmospheric Research, Boulder, Colorado, USA, 42 pp. + 170 maps, 1988.

Warren, S. G., Eastman, R. M., and Hahn, C. J.: A survey of changes in cloud cover and cloud types over land from surface, J. Climate, 20, 717-738, 2007.

Wibig, J.: Cloudiness variations in Łodz in the second half of the 20th century, Int. J. Climatol., 28, 479-491, 2008.

Wild, M.: Global dimming and brightening: A review, J. Geophys. Res., 114, D00D16, doi:10.1029/2008JD011470, 2009.

Wild, M.: Enlightening global dimming and brightening, B. Am. Meteorol. Soc., 93, 27-37, 2012.

Woodruff, S. D., Worley, S. J., Lubker, S. J., Ji, Z., Freeman, J. E., Berry, D. I., Brohan, P., Kent, E. C., Reynolds, R. W., Smith, S. R., and Wilkinson, C.: ICOADS Release 2.5: extensions and enhancements to the surface marine meteorological archive, Int. J. Climatol., 31, 951-967, 2011.

Wright, P. B.: Problems in the Use of Ship Observations for the Study of Interdecadal Climate Changes, Mon. Weather Rev., 114, 1028-1034, 1986.

Xia, X.: Spatiotemporal changes in sunshine duration and cloud amount as well as their relationship in China during 1954-2005, J. Geophys. Res., 115, D00K06, doi:10.1029/2009JD012879, 2010.

You, Q., Kang, S., Flügel, W.-A., Sanchez-Lorenzo, A., Yan, Y., Huang, J., and Martin-Vide, J.: From brightening to dimming in sunshine duration over the eastern and central Tibetan Plateau (1961-2005), Theor. Appl. Climatol., 101, 445-457, 2010. 
Young, G. H. F., McCarroll, D., Loader, N. J., and Kirchhefer, A.: A 500-year record of summer near-ground solar radiation from tree-ring stable carbon isotopes, Holocene, 20, 315-324, 2010.
Zelinka, M. D. and Hartmann, D. L.: Why is longwave cloud feedback positive?, J. Geophys. Res., 115, D16117, doi:10.1029/2010JD013817, 2010. 